\title{
Failure Modeling of Bridge Components Subjected to Blast Loading Part II: Estimation of the Capacity and Critical Charge
}

\author{
Russ Quintero"), Jun $\mathrm{Wei}^{2}{ }^{2}$, Nestore Galati ${ }^{3)}$, and Antonio Nanni ${ }^{4) *}$
}

(Received October 25, 2007, Accepted December 20, 2007)

\begin{abstract}
The purpose of this paper is the assessment of the capacity of the reinforced concrete (RC) elements of an arch bridge when they are subjected to contact and near-contact explosive charges of various amounts, and the estimation of the critical charges for these components. The bridge considered is the Tenza Viaduct, a decommissioned structure south of Naples, Italy. Its primary elements, deck, piers and arches were analyzed. The evaluation was accomplished via numerical analyses that made possible to obtain the elements dynamic response when they are exposed to blast loading conditions. To evaluate the member's capacities, failure criteria for deck, piers and arches were proposed based on concrete damage parameters. Additionally, curves relating the explosive charge to the residual capacity and to damage level of the elements were also developed. The results of this work were taken into account to investigate the progressive collapse of the global structure.
\end{abstract}

Keywords : blast loading, bridge collapse, critical charges, dynamic damage model, explicit FEM, free air explosion, progressive collapse

\section{Introduction}

Recent terrorist events have increased the need for evaluation of structures under the effect of blast loads. However, most of the research conducted on the performance of structures subjected to explosions has been carried out on buildings rather than bridges. ${ }^{1}$ Understanding the performance of a bridge and its components when subject to explosive in- or near- contact charges is critically important for improving the security of the transportation infrastructure against acts of terrorism. ${ }^{2}$

The structure under investigation is one of the two arch bridges of the Tenza Viaduct near Salerno, Italy (see Fig 1.). The bridge of reference is made entirely of reinforced concrete (RC) and consists of a main span and two approach ramps. The main span is an open spandrel arch $120 \mathrm{~m}$ long and $50 \mathrm{~m}$ tall. The bridge deck and its integral wall piers are supported by a ribbed, solid cross section, and fixed-fixed arch. Each approach span is $30 \mathrm{~m}$ long and supported on multiple wall piers of varying heights. Each individual pier is made of two RC columns connected over their entire height by an RC panel.

The bridge was built in the sixties during the economic growth after the Second World War. In the eighties, the bridge was

\footnotetext{
${ }^{1)}$ Dept. of Civil, Architectural and Environmental Engineering, University of Missouri-Rolla, Rolla, MO 65409-0710, USA.

${ }^{2)}$ Dept. of Mechanical and Aerospace Engineering, Arizona State University, PO Box 37100, Phoenix, AZ 85069-7100, USA.

${ }^{3)}$ Structural Group, Inc., Strengthening Division, Elkridge, Maryland 21075, USA.

${ }^{4)}$ Dept. of Civil, Architectural and Environmental Engineering, University of Miami, Coral Gables, FL 33146-2509, USA.E-mail: nanni@miami.edu

Copyright (c) 2007, Korea Concrete Institute. All rights reserved, including the making of copies without the written permission of the copyright proprietors.
}

retrofitted to resist seismic loads. The strengthening consisted of the enlargement of the piers and arches cross-sections and linking the arches with a slab. Additional details on the strengthening work can be found in Nanni et al. ${ }^{2}$

This paper presents the evaluation of the bridge components based on the residual capacity of each element after a blast event. The capacity was obtained through numerical analysis using the finite element method (FEM). All simulations were carried out using the commercial ABAQUS/Explicit FEM code. ${ }^{3}$ This code provides the capability to simulate a blast load by applying an incident wave corresponding to a given time-history overpressure, the coordinates of the explosive, the location where the front wave hits the structural element, the properties of the medium where the wave moves and other related parameters. ${ }^{3}$ ABAQUS also allows the definition of the dynamic constitutive properties for concrete and steel reinforcement as a function of the strain rate. This permits to take into account the variation of the material properties like the strength when they are under conditions where the load changes in a very rapid way.

The critical charges were determined by defining failure criteria for the different bridge members. Generally, the failure is defined as a function of the rotation at the ends of the structural element or as a function of the deflection at the midspan. ${ }^{1}$ Due to the size of the elements analyzed in this work, its cross-sectional shape and the localized nature of the expected response different failure criteria are required. In this paper a "level of damage" approach is proposed. The member's capacities were evaluated by defining members specific failure criteria based on the concrete level of damage for piers and arches and on the crater size for the deck. In addition, for piers and arches, correlations between charge weight and levels of damage to the explosive charges were also obtained. 


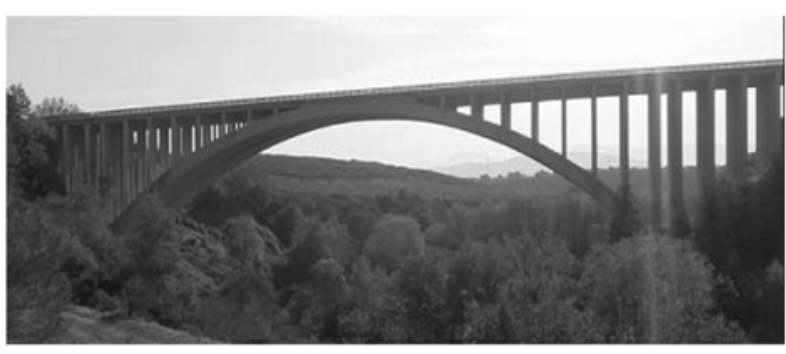

Fig. 1 Tenza Viaduct, Salerno, Italy.

Capacity curves were defined by estimating the capacity of the bridge components corresponding to several charges placed at selected locations. The intersection of the load demand with a capacity curve corresponds to the critical charge for the element analyzed.

Due to security concerns, the weight of the charges is not explicitly shown and fictitious units are used: Unit Charge Weight (UCW). Requests for a full report can be made to the research sponsor, The Technical Support Working Group (TSWG).

\section{Material properties}

Materials properties were obtained from tests carried out on specimens collected at several locations of the bridge for the three primary RC elements. Quasi-static and dynamic tests were conducted in order to determine the static and dynamic constitutive properties of concrete and steel at various strain rates. ${ }^{2}$ Four types for material samples were extracted from the bridge: original concrete and original steel, both used for the bridge initial construction in the $1960 \mathrm{~s}$, new concrete and steel used for strengthen the bridge during the 1990s. Results showed that, although, original material properties were a little higher than the new ones the differences between them are negligible. ${ }^{2}$ Therefore, unique properties for concrete and for steel reinforcement were used in this work.

Table 1 summarizes the static and dynamic material properties for the concrete used in the simulations based on a strain rate of $100 \mathrm{~s}^{-1}$. In addition, to take into account the influence of the shear stress, a dilatation angle equal to $36.31^{\circ}$ was assumed for all cases to allow the development of compression membrane in the members. This parameter is very important because it affects volume change during material yielding and influences on the grade of confinement of the concrete. A low value of the dilatation angle characterizes a high confined concrete because little volume change occurred after yielding. On the other hand, a high value of this parameter describes a low confinement behavior and a more noticeable change in volume, which is associated to shear stresses, take place in the material. The dilation angle used in this work correspond to a relatively low confinement, however the confinement will be provided by transversal steel rein-

Table 1 Static and dynamic concrete properties.

\begin{tabular}{c|c|c|c|c|c|c|c}
\hline Member & $\begin{array}{c}\mathrm{E}_{\mathrm{c}} \\
(\mathrm{GPa})\end{array}$ & $v$ & $\begin{array}{c}\mathrm{f}_{\mathrm{cm}} \\
(\mathrm{MPa})\end{array}$ & $\begin{array}{c}\mathrm{f}_{\mathrm{cd}} \\
(\mathrm{MPa})\end{array}$ & $\varepsilon_{\mathrm{cd}}$ & $\begin{array}{c}\mathrm{f}_{\mathrm{td}} \\
(\mathrm{MPa})\end{array}$ & $\begin{array}{c}\mathrm{G}_{\mathrm{Fd}} \\
\left(\mathrm{J} / \mathrm{m}^{2}\right)\end{array}$ \\
\hline \hline Arch & 26.4 & 0.2 & 31.1 & 71.3 & 0.00470 & 19.4 & 230 \\
\hline Deck & 32.2 & 0.2 & 46.4 & 93.7 & 0.00412 & 22.9 & 278 \\
\hline Pier & 26.1 & 0.2 & 30.3 & 70.4 & 0.00476 & 19.2 & 227 \\
\hline
\end{tabular}

forcement include in the models for arch and pier. For the deck, the grade of confinement given by this dilation angle was considered appropriate for this type of element.

Only one kind of concrete curve based on a single value of strain rate was used for all elements modeled (arch, pier and deck) and no transition regions from high strain rates to low strain rates material was included in the models. This might lead to think that the critical charges as well as levels of damage found here could be underpredicted in areas where the strain rates are not as high as near the stand-off point. However, patterns of damage are found in localized areas, close to the region where the front wave impinges the structural elements, where strain rates are expected to be as high as those used for the concrete material curve.

For the steel reinforcement, the static elastic modulus, $\mathrm{E}_{\mathrm{s}}$, and the Poisson's ratio, v, were assumed equal to $200 \mathrm{GPa}$ and 0.30 , respectively. The dynamic yield strength for the steel reinforcement is summarized in Table 2 as a function of the strain rate.

Two ways were used to include the steel reinforcement in the models. For pier, truss elements were used to represent the longitudinal and transversal steel while for arch and deck rebar layer capability allowed to model the reinforcement. Several stressstrain curves depending on strain rates were included for representing the behavior of the steel.

Details on the materials models adopted here for concrete and steel are reported in the companion paper. ${ }^{7}$ In that instance, it was obtained good agreement as it was compared the patterns of damage obtained from numerical simulation of RC slabs to those observed in test specimens. That allowed us to verify that the assumed models work well for this kind of simulations.

At this time no validation of the capacity curves or damage curves was performed because experimental results or instrumented measurements for the type of elements analyzed here are not available. Testing to destruction of the bridge is planned in the near future.

\section{Blast loading}

The formulation to obtain the time-history overpressures acting on the structural members was presented and validated in the companion paper. ${ }^{7}$ In particular, the comparison between laboratory and numerical blast results on RC slabs demonstrated the accuracy of the blast loading formulation. Three loading conditions are considered in this study: contact charges, short-distance charges, and charges on ground. ${ }^{2}$ The explosive charges used to obtain the time-history overpressures for the analysis were TNT equivalent weights and the corresponding pressure-time-history equations for these loading conditions are presented in [7].

It should be pointed out that ABAQUS allows considering two types of incident waves: plane and spherical front waves. The plane front wave can be used to represent an incident wave with

Table 2 Dynamic steel reinforcement yield strength.

\begin{tabular}{c|c}
\hline Strain rate $(1 / \mathrm{sec})$ & $\mathrm{f}_{\mathrm{y}}(\mathrm{MPa})$ \\
\hline \hline 0.0001 & 388.3 \\
\hline 174 & 547.2 \\
\hline 562 & 626.4 \\
\hline
\end{tabular}


a distant source, while the spherical front wave characterizes a near-source incident wave. In this research, a spherical front wave was used for all cases considered because the distances of interest, which vary from $0.30 \mathrm{~m}$ to $3.00 \mathrm{~m}$, correspond to near-source incident waves.

\section{Failure criteria and critical charges for structural elements}

\subsection{Failure criterion for deck}

In the case of the deck subject to in- and near-contact charges, it is not possible to define a failure criterion like the one for arch and pier because the effect of these charges is to create a crater on the surface where they burst. ${ }^{10}$ Instead, a ratio of damage deck will be determined.

The effect of the blast event is then accounted for by determining the ratio $\eta \in[0,1]$ between the area damaged by the explosion and the total area of the deck or the portion of interest. This ratio may vary between 0 and 1 , with a value of 1 corresponding to the complete loss of the deck. However, the complete damage of the deck does not necessarily represent the collapse of the bridge.

\subsection{Failure criterion for piers and arches}

After the blast event, since piers and arches primarily carry axial loads, the failure criterion is expressed as:

$$
N_{c}=N_{d}
$$

where $N_{d}$ represents the axial demand determined from the static structural analysis of the bridge, and $N_{c}$ is the element capacity determined as a function of the damage indices. ${ }^{7}$ The damage indices are obtained from the FEM analysis for each loading case is explained next.

The axial load capacity, $N_{c}$, is determined as a function of the weighed average compression damage, $d_{\text {ave }}$, at the most damaged cross-section of the structural member by means of the following expression:

$$
N_{c}=f_{c}^{\prime} A_{0}\left(1-d_{\text {ave }}\right)+\sum_{i=1}^{n} A_{S_{i}} f_{S_{i}}
$$

where:

$f_{c}^{\prime}=$ the compressive strength of the undamaged concrete,

$A_{0}=$ the cross-sectional area of the undamaged element,

$d_{\text {ave }}=$ the weighed average compression damage in the section,

$A_{S_{i}}=$ the area of the each reinforcing steel bar out of the damaged area,

$f_{S_{i}}=$ the strength of the steel bar.

Because no unique value of damage is available for the whole cross-section where the damage is measured, an average damage in the cross-section was adopted to determine the capacity of the member. The average damage is then obtained as follow:

$$
d_{\text {ave }}=\frac{\sum_{j=1}^{n_{e l}} d_{j} A_{e j}}{\sum_{j=1}^{n_{e l}} A_{e j}}
$$

where:

$d_{j}=$ the damage parameter for the concrete damage model ${ }^{3}$ and it is an output parameter obtained from the numerical analysis for each individual finite element of the critical cross-section of the member under investigation.

$A_{e j}=$ the corresponding area of each individual finite element in that cross-section where damage is measured.

\subsection{Critical charge for deck}

The critical charges for the deck were determined considering the geometry shown in Fig. 2. The dimensions of the deck supporting beams and the boundary conditions are also shown in Fig. 2.

For the numerical analysis, a charge was placed in contact with the deck at its center. Because of structural symmetry, only a quarter of the deck was analyzed, to reduce the computational time. A typical damage distribution corresponding to a $50 \mathrm{UCW}$ charge in contact with the deck is shown in Fig. 3.

Table 3 and Fig. 4 show the ratio $\eta$, defined as the damage area to the total area of the deck, as a function of the charge weight. This figure shows two branches: one, corresponding to values of charges up to $25 \mathrm{UCW}$ and $\eta=0.5$ (the size of the crater is half the area of the deck), that has a steep slope; and one for charges above $25 \mathrm{UCW}$ with a lower gradient till the crater size covers almost the entire deck area $(\eta=0.92)$ for a $325 \mathrm{UCW}$ charge. This charge was the maximum value used in the simulation as it corresponds to the maximum allowed when testing near the south ramp of the bridge without damaging the surrounding buildings. ${ }^{2}$ Such charge could cause the damage of the two longitudinal interior support beams, but leave the two exterior beams

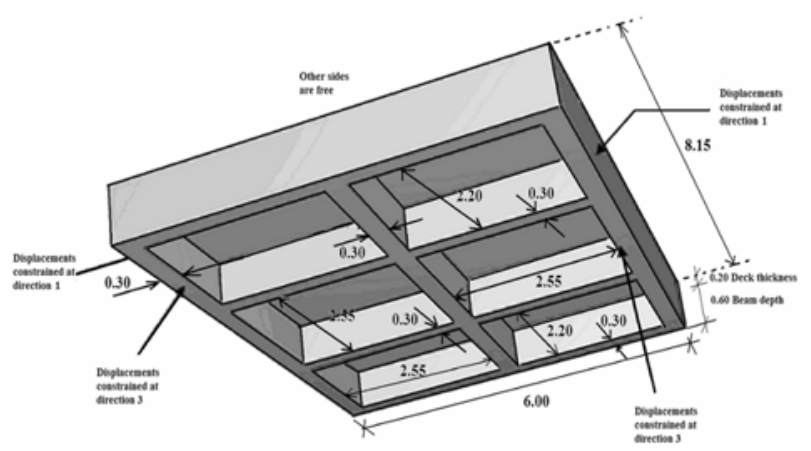

Fig. 2 Geometry and boundary conditions for deck and supporting beams-charge located at the center of the deck (dimensions in meter).

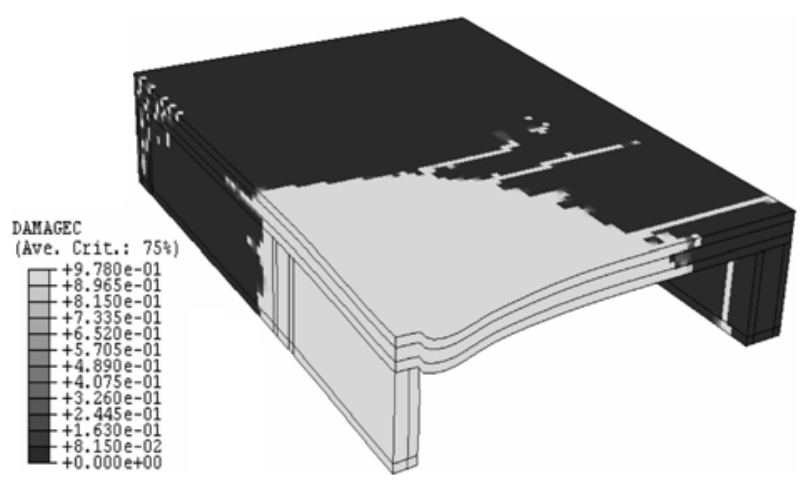

Fig. 3 Damaged deck at 4 milliseconds after blasting under 50 UCW contact charge. 
Table 3 Deck damage factor $\eta$ for different charge weights.

\begin{tabular}{c|c|c|c|c|c|c|c|c}
\hline Charge, UCW & 1 & 5 & 10 & 20 & 50 & 100 & 200 & 325 \\
\hline \hline Ratio $\eta$ & 0.17 & 0.25 & 0.33 & 0.47 & 0.58 & 0.67 & 0.75 & 0.92 \\
\hline
\end{tabular}

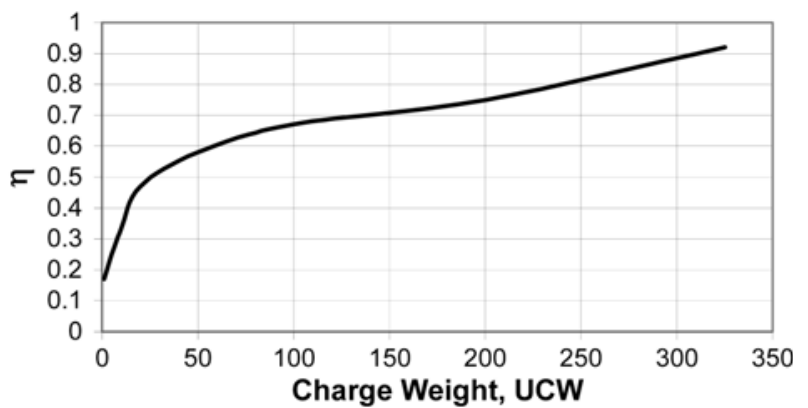

Fig. 4 Damage ratio at the deck as a function of the charge weight.

standing and, consequently, without additional damage to the substructure.

\subsection{Critical charges for piers}

The behavior of the piers was analyzed considering an I-section column as shown in Fig. 5. This pier type belongs to the approach ramp near to the arch. It was chosen for the numerical analysis because it is the tallest in the bridge and is characterized by the largest cross-sectional area. The charge sizes determined for such elements are considered the upper bound.

The cross-section of the column is comprised of two portions: the central wall or web of the section, and the flanges. The web of the section presents a very weak plane as it is loaded normally. In contrast, the portion corresponding to the flanges provides a more resistant capability in the same plane.

As compared to solid sections (rectangular and quadrilateral), the I-section damage seems to be more localized on the web portion, while the flanges may be less affected by charges of certain magnitude. Under some relatively low charges, high values of damage can easily be produced throughout the web even though this would not cause failure of the element since the flanges provide enough bearing capacity. On solid sections, the damage seems to be more distributed throughout the area of the cross-sec- tion and a possible failure is less complex to identify.

The mechanical behavior of the piers subjected to several blast scenarios for different charges and standoff distances were characterized. This characterization allows the engineer to determine, based on the level of damage and estimations of the pier's ability to continue supporting static loads, what and how many structural elements, if removed, would result in the progressive collapse of the bridge.

\section{Analyses}

Taking advantage of the symmetry, only half of the pier was modeled. All degrees of freedom were restricted at the base of the pier and, at the upper end, only the vertical movement was allowed for the application of the axial load. A non uniform mesh was used for the simulation of this member. A more refined mesh was used at the lower end of the pier near the area directly invested by the blast waves. For the upper part, a less dense mesh was used. This allowed reducing the computational effort without losing accuracy in the area of interest.

Five representative blast scenarios were considered as described in Table 4 and Fig. 6. In Scenario I, the charge is placed perpendicular to the web and three different charges (2.5, 5 and 10 $\mathrm{UCW}$ ) were located at a distance (R) of $0.3 \mathrm{~m}$ from the face of the web, and at a height (h) of $1 \mathrm{~m}$ measured from the base of the column. For Scenario II, the charge is placed perpendicular to one flange and three charges of 3,4 , and 5 UCW were considered at $\mathrm{R}=0.3 \mathrm{~m}$ from the flange and at $\mathrm{h}=1 \mathrm{~m}$ from the base. In Scenario III, the charge is placed on the arch perpendicular to the web as for Scenario I. The charge is located at $\mathrm{R}=3.0 \mathrm{~m}$ and at $\mathrm{h}=2.6 \mathrm{~m}$ from the base. Charges of 10,11, and $22 \mathrm{UCW}$ were analyzed for this scenario. For Scenario IV, the charge is placed perpendicular to the web, halfway from two piers at $\mathrm{R}=1.89 \mathrm{~m}$ from the face of each web. Cases with charges of 80, 100, 110, 120 and $200 \mathrm{UCW}$ were analyzed. In the last Scenario, the charge is placed perpendicular to flanges equidistant from two piers. The distance between the standoff points and the explosion source is $R=1.2 \mathrm{~m}$. Five cases of charges (30, 40, 50, 60 and $100 \mathrm{UCW}$ ) were analyzed for this scenario.

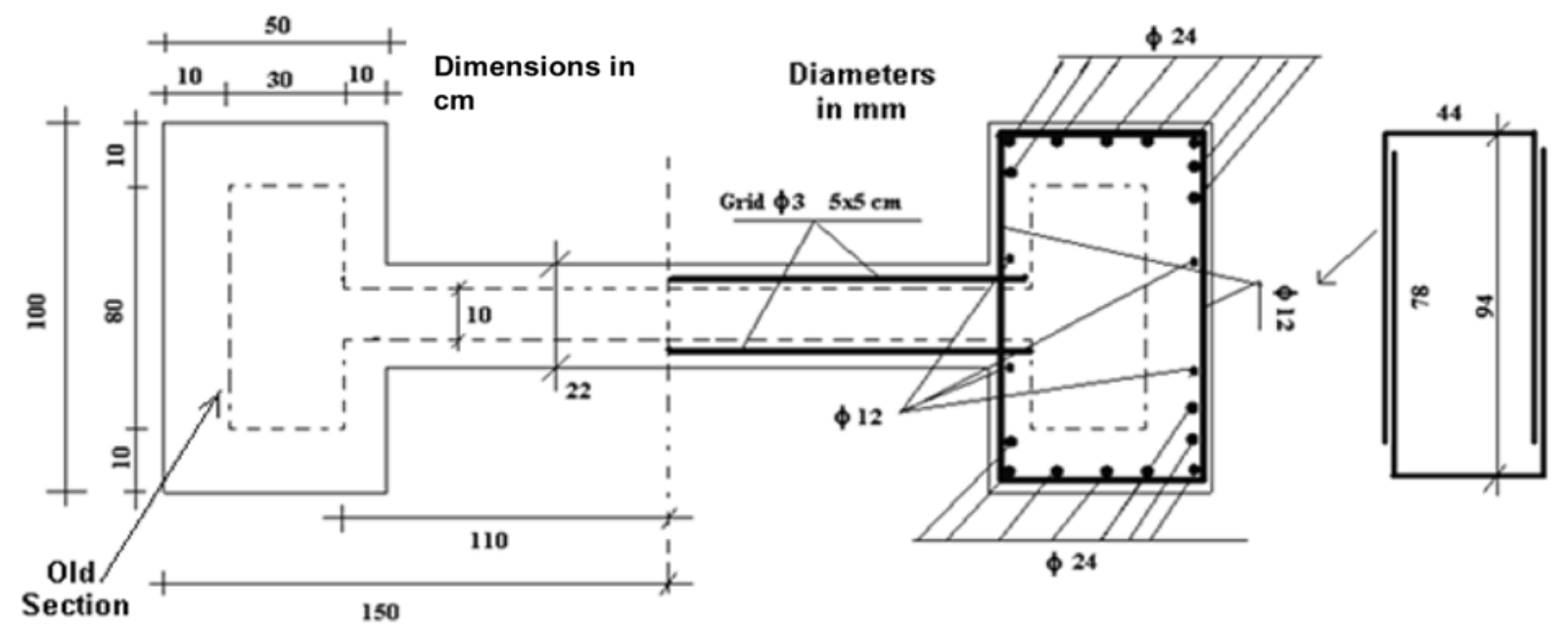

Fig. 5 Typical cross-section of a pier and longitudinal and transversal reinforcement-dashed line depicted the cross-section before the structural strengthening. 
Table 4 Summary of simulation results.

\begin{tabular}{|c|c|c|c|c|c|c|}
\hline Scenario & $\mathrm{R}(\mathrm{m})$ & $\mathrm{h}(\mathrm{m})$ & W (UCW) & Ave. damage & $\mathrm{N}_{\mathrm{c}}(\mathrm{kN})$ & Condition \\
\hline \multirow{3}{*}{ I } & 0.3 & 1.0 & 2.5 & 0.34 & 19,100 & ok \\
\hline & 0.3 & 1.0 & 5.0 & 0.52 & 10,100 & ok \\
\hline & 0.3 & 1.0 & 10.0 & 0.92 & 254 & fail \\
\hline \multirow{3}{*}{ II } & 0.3 & 1.0 & 3.0 & 0.35 & 18,600 & ok \\
\hline & 0.3 & 1.0 & 4.0 & 0.45 & 13,200 & ok \\
\hline & 0.3 & 1.0 & 5.0 & 0.98 & 11.2 & fail \\
\hline \multirow{3}{*}{ III } & 3.0 & 2.6 & 10.0 & 0.03 & 41,300 & ok \\
\hline & 3.0 & 2.6 & 11.0 & 0.05 & 39,200 & ok \\
\hline & 3.0 & 2.6 & 22.0 & 0.98 & 11.2 & fail \\
\hline \multirow{5}{*}{ IV } & 1.9 & 1.0 & 80.0 & 0.15 & 31,300 & ok \\
\hline & 1.9 & 1.0 & 100.0 & 0.27 & 23,000 & ok \\
\hline & 1.9 & 1.0 & 110.0 & 0.29 & 22,300 & ok \\
\hline & 1.9 & 1.0 & 120.0 & 0.32 & 20,100 & ok \\
\hline & 1.9 & 1.0 & 200.0 & 0.50 & 10,800 & ok \\
\hline \multirow{5}{*}{$\mathrm{V}$} & 1.2 & 1.0 & 30.0 & 0.11 & 34,600 & ok \\
\hline & 1.2 & 1.0 & 40.0 & 0.45 & 13,000 & ok \\
\hline & 1.2 & 1.0 & 50.0 & 0.47 & 12,100 & ok \\
\hline & 1.2 & 1.0 & 60.0 & 0.57 & 8,120 & ok \\
\hline & 1.2 & 1.0 & 100.0 & 0.87 & 716 & fail \\
\hline
\end{tabular}
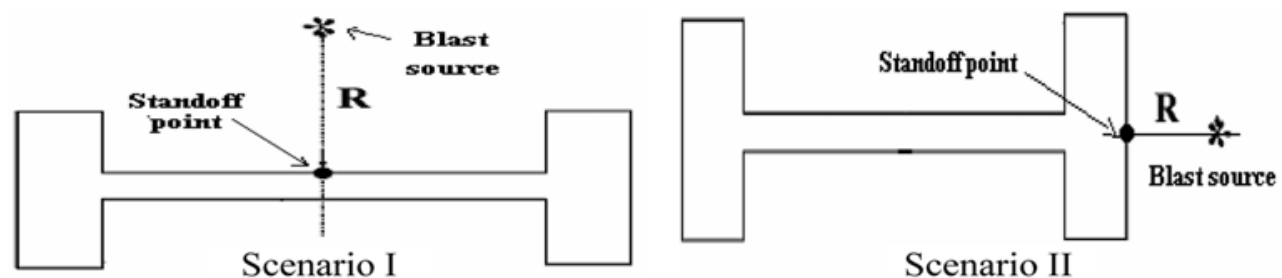

Scenario II
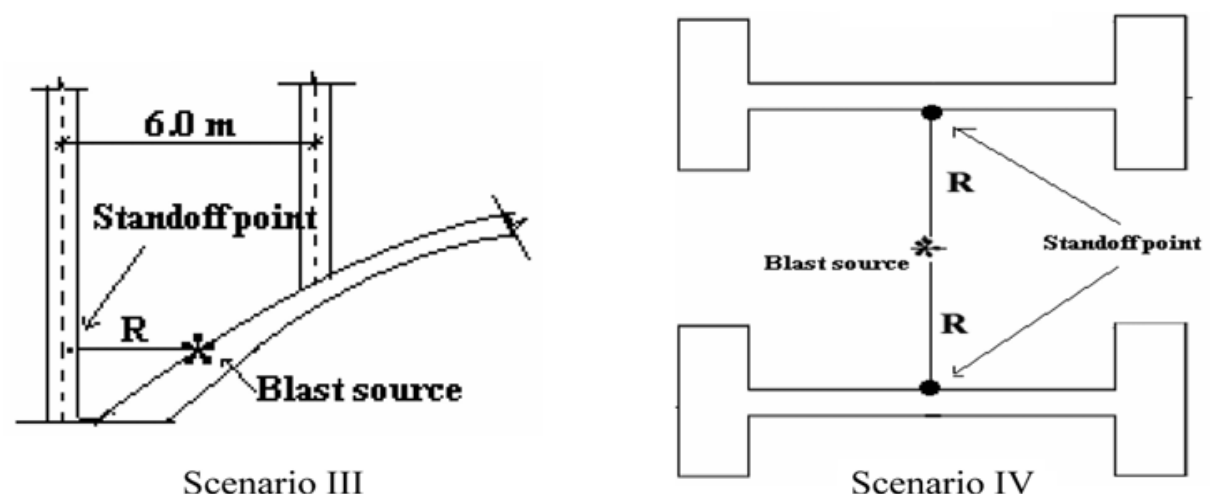

Scenario III

Scenario IV

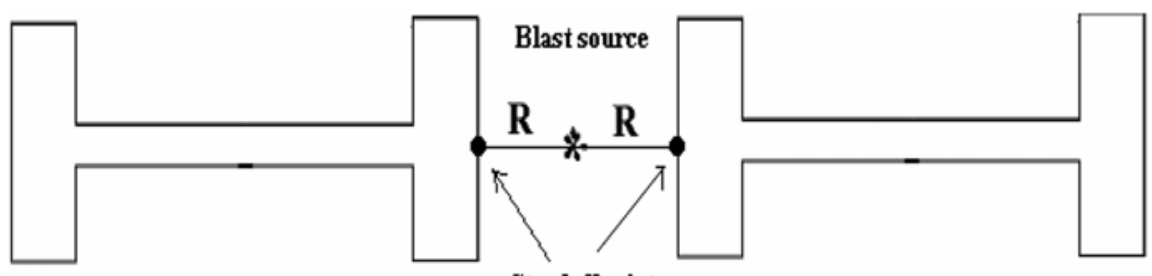

Standoff point

Scenario V

Fig. 6 Explosion Scenarios.

\section{Results}

The critical charge amounts were obtained by comparing the residual capacity $\left(N_{c}\right)$ from the FEM analysis to the demand $\left(N_{d}\right)$ resulting from self weight. The demand load $\left(N_{d}\right)$ was deter- mined to be equal to $1,060 \mathrm{kN}$ for the element under investigation. In Scenario I, a charge of $10 \mathrm{UCW}$ can cause significant damage to reduce the capacity of the pier to a value below the demand and therefore, the element fails. For Scenario II, the critical charge was found to be 5 UCW. This shows how a small 
charge located at a short distance can produce a massive amount of damage that reduces drastically the capacity of the pier. In scenario III, where the charge is in contact with the arch and its amount is the same that produce the arch failure (25 UCW), it was found that this charge also cause the failure of the pier. A charge as small as of $22 \mathrm{UCW}$ becomes critical for the pier in this scenario. Results from scenario IV (intended to identify the charge that causes the simultaneous failure of two adjacent piers), show that a charge of 200 UCW could damage more than 50 percent of the cross section; however, the residual capacity was not below the demand. The charges used in the simulations, damaged a big part of the web of the section, as shown in Fig. 7, leaving, however, a considerable part of the flanges that are still capable of resisting the vertical loads. In Fig. 7, the light gray represents the area where the damage was maximum (web and part of the flange) and the progressively dark areas correspond to low damage (flange). For scenario V, a 100 UCW explosive charge is found to causes approximately an 87 percent of damage, sufficient to cause the failure of the member. This scenario is more dangerous than the previous one because two piers of the same bent can reach the failure with a charge half the size of the one used for Scenario IV. A contour of the degradation of the material is presented in Fig. 8. There, the light gray represents the area where the degradation was maximum (a significant part of the flange and the whole web at the base of the pier).and at the dark area the degradation was very low or null (upper part of the pier). Table 4 summarizes the scenarios with the distances between the charge locations to the standoff point on the pier, height from the ground, charges, and the result found for each of them: average damage, residual capacity and final condition of the pier after a blast load related to corresponding weight charge. In addition, curves of capacities and demand as well as damage of the pier as function of the explosive charge weight, as that shown in Fig. 9, were drawn. They will be explained later on.

\section{Critical charge for arch}

Also for the arch, computation time was reduced by using symmetry of the structure. The geometry, dimensions, boundary

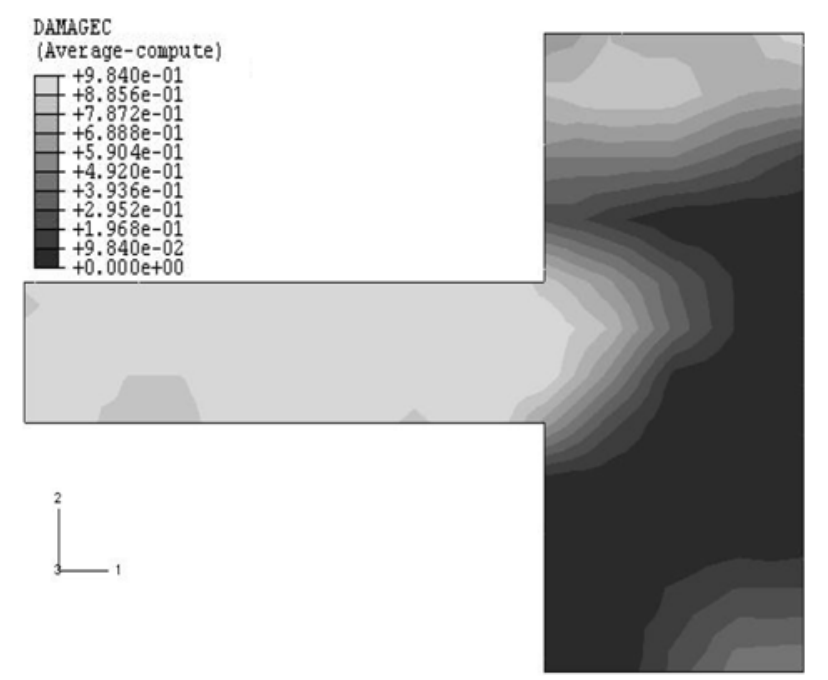

Fig. 7 Contour of damage in a cross-section of a pier (Scenario IV, 200 UCW, R = $1.9 \mathrm{~m}$ ). conditions of the arch, and blast location are shown in Fig. 10. For the connection between the arch base and the foundation, a fixed boundary condition was assumed.

The loads acting on the arch represent the self weight of the

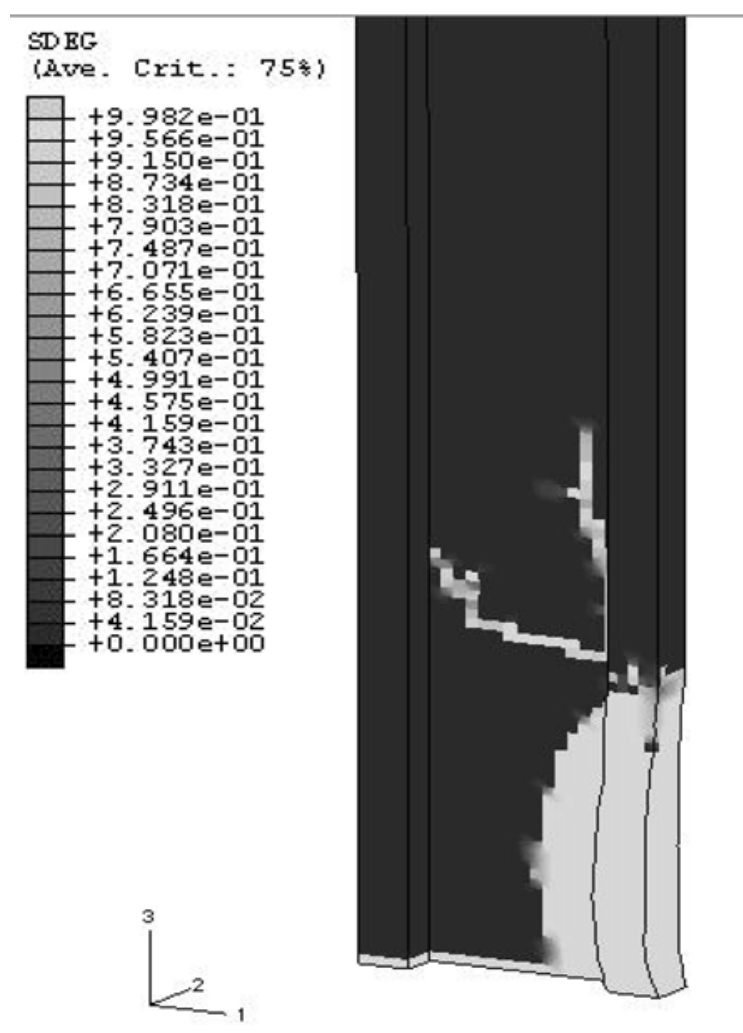

Fig. 8 Contour of material degradation (Scenario V (100 UCW, R $=1.2 \mathrm{~m}$ ).

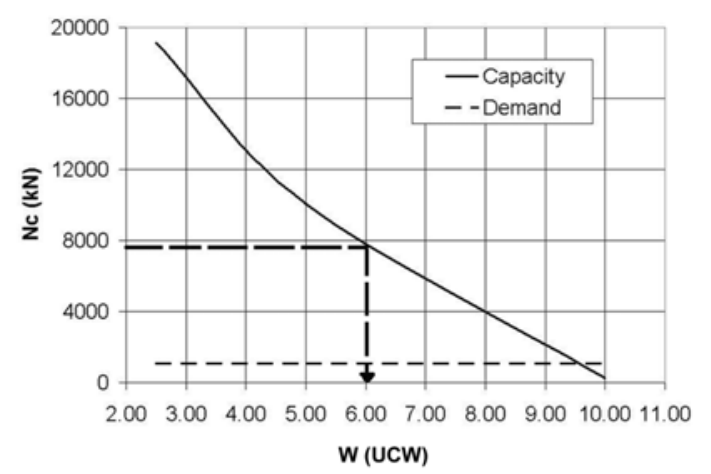

(a) Capacity and Demand

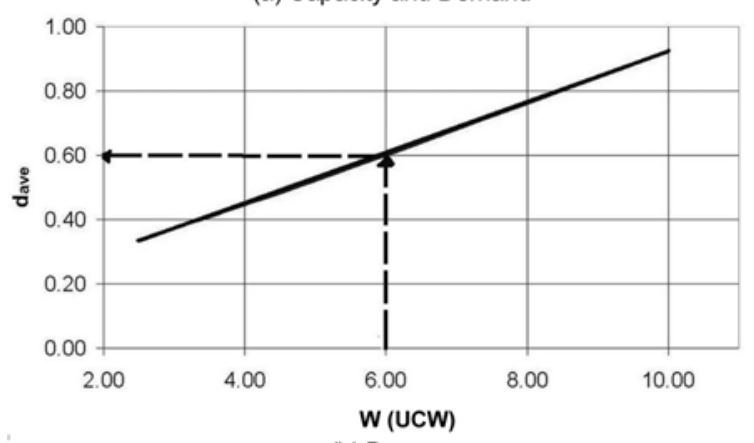

(b) Damage

Fig. 9 Curves of (a) capacity and demand (b) damage of the pier as a function of the explosive charge weight at critical section, Scenario I, $\mathrm{R}=0.3 \mathrm{~m}$. 


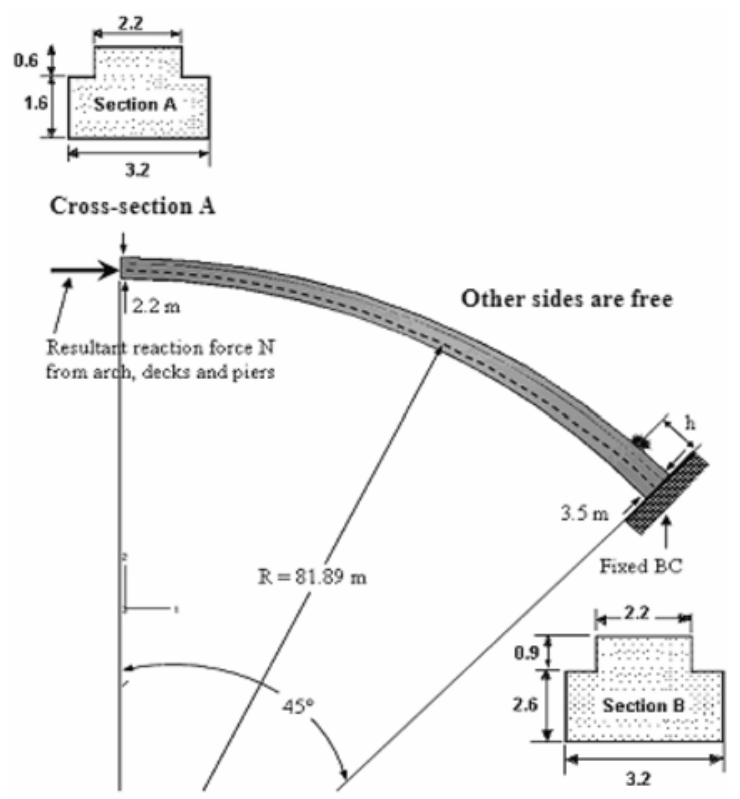

Fig. 10 Geometry of the Arch-arc length at mid layer (all dimension in meters, drawing not to scale).

superstructure. The arch was subject to a charge located at a distance, $h$, of $6.15 \mathrm{~m}$ from the end at the foundation as shown in . Like the other elements, the blast loading parameters were calculated using the equations reported in [7].

Using these material properties presented in Table1 and Table 2, the blast loading parameters and the arch geometry, the capacity of the arch was obtained using Eq. (2) in the same way as for the piers.

Five analyses were performed. The residual compression capacities obtained for $20,25,30,50$, and $100 \mathrm{UCW}$ charge were $71,500,20,900,16,600,6,000,2,100 \mathrm{kN}$, respectively. It was observed that the arch failure occurred for charges of 25, 30, 50 and $100 \mathrm{UCW}$. For these cases, the residual capacity of the arch was lower than the axial load acting on it.

The analysis indicates that the critical charge weight causing the arch to fail is $25 \mathrm{UCW}$. For this charge, it is observed some local yielding in the steel rebar and the concrete is heavily cracked and the loss of concrete causes the buckling of the steel bars. A curve of the residual capacity of the arch as a function of the charges weights was developed. The relationship between demand and residual capacity of the arch after blasting is shown in Fig. 11. It can be observed that increasing the charge weight results in a rapid decrease in the residual capacity of the arch. The intersection point between the demand line and the capacity curve gives a critical charge weight of $25 \mathrm{UCW}$ for a member with this cross-sectional area. Finally, Fig. 12 shows the damage pattern of the arch when subjected to a 100 UCW charge allowing one to visualize that for higher charges the damage covers the entire cross section. On the contrary, for lower charges only partial damage of the cross sectional area was found.

\section{Discussion}

Curves relating the explosive charges to the remaining capacity of the pier and explosive charges to average damage for the most affected cross-section of the member were created. These curves can be used to estimate the critical explosive charge and

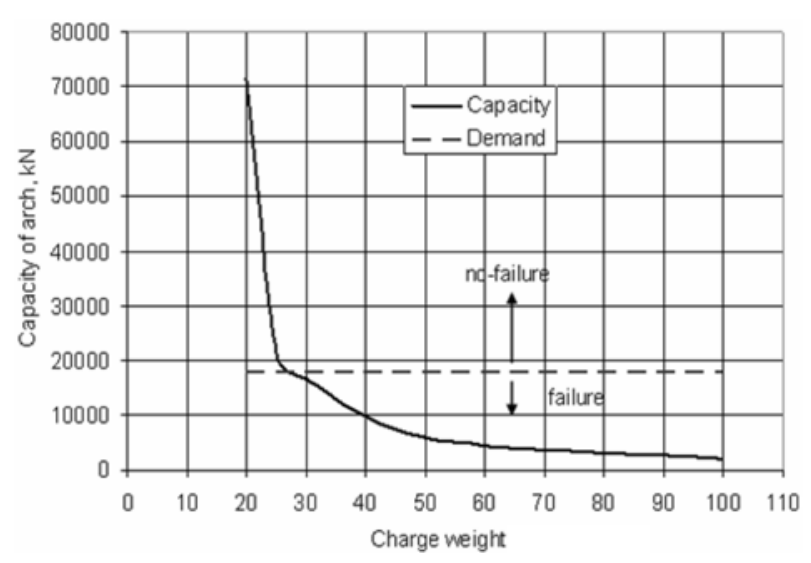

Fig. 11 Demand load and capacity of the arch after blasting vs. charge weight.

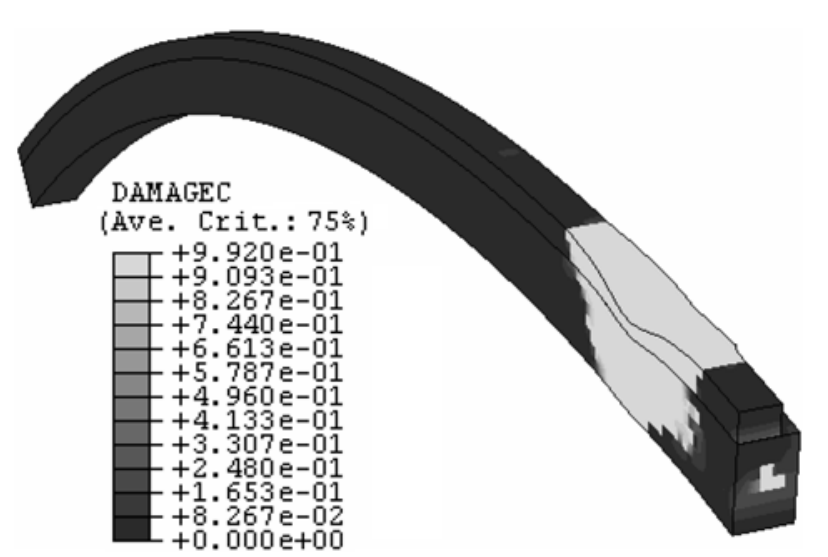

Fig. 12 Damage pattern of arch subjected to a 100 UCW charge burst (thorough cross-section damage).

the corresponding damage for any other demand load. For example, if the demand load is increased (dashed line in Fig. 9) then the effect of this new value can be evaluated by means of the capacity curve. It can be observed that as the load increases, the charge needed to cause the failure decreases. In addition, this new critical charge can be entered into the damage curve and one can obtain a value of average damage for the new demand load. The demand load used to determine the failure charge in this analysis was comprised basically of the selfweight of the superstructure and the weight of the element analyzed.

With regard to the results found for scenarios I and II for pier (see Table 4), it can be observed that the level of damage from these simulations is higher than possibly expected. In fact, it was found that even very small charges placed at close distance would cause high levels of damage and even failure. Such variation was thought to exist because the model considered is based on continuum damage mechanics which does not allow the removal of the heavily damaged elements that, therefore, continue transferring unrealistic loads to other elements. This hypothesis, which was not confirmed in this work, should be verified by comparing these numerical results with those obtained from other programs, for example, AUTODYN, which has the capability of removing from the analysis those elements that have reached a stated damage level base on deformations. ${ }^{11}$ 


\section{Conclusions}

Finite element analysis was conducted to investigate the residual capacity of piers and arches and the damage area of the deck of the Tenza Viaduct under blast loading conditions. Similar results or instrumented measurements that allowed a comparison to those obtained here are not available. Further research considering various bridge models is needed before generalizing the conclusion drew from this research.

Based upon the numerical simulations, the following conclusions are drawn:

1) The damage area for the deck varies in a bi-linear fashion. The first branch rapidly reaches more that fifty percent loss of the total area of the deck with a $25 \mathrm{UCW}$ charge. For higher charges, the damage area progresses at a slower rate. The complete damage of the deck could be found for a charge equal to the maximum amount allowed for testing near the south ramp of the bridge without damaging the surrounding buildings. Such charge could cause the damage of the two inside longitudinal beams of the portion of the deck between two piers, leaving the other two outside beams standing without additional damage to the rest of the structure.

2) For arch and piers, curves relating the residual capacity and average damage for the most affected cross-section were determined as a function of the charge amount. Each graph allows determining the critical charge for the elements once the demand is known for a given distance. Similar curves can be generated and used to estimate the critical explosive charge and the corresponding damage for any specified demand load and any member cross-section.

3) The possible threats for the piers were studied by determining the critical charges corresponding to five possible scenarios. Scenario V resulted to be very dangerous because two adjacent piers can reach failure for a relatively low charge and may initiate progressive collapse.

4) The critical explosive charge for the arch was found to be 25 UCW. For this charge, local yielding of the steel bars occurred and the concrete was heavily cracked. The loss of concrete produced of buckling of the steel bars followed by collapse.

\section{Acknowledgments}

The authors are thankful to The Technical Support Working Group for the funds provided to support this research (TSWG Contract Number N4175-05-R-4828).

\section{Notation}

$\mathrm{d}_{\mathrm{ave}}=$ Average compression damage in the section considered

$\mathrm{d}_{\mathrm{c}} \quad=$ Degradation of compressive elastic modulus of concrete

$\mathrm{d}_{\mathrm{j}} \quad=$ Damage obtained from the numerical analyses for each finite element $\mathrm{j}$

$\mathrm{d}_{\mathrm{t}} \quad=$ Degradation of tensile elastic modulus of concrete

$\mathrm{f}_{\mathrm{c}}^{\prime} \quad=$ Static compressive strength of concrete

$\mathrm{f}_{\mathrm{cd}} \quad=$ Dynamic compressive strength of concrete

$\mathrm{f}_{\mathrm{cm}} \quad=$ Average static compressive strength of concrete

$\mathrm{f}_{\mathrm{td}} \quad=$ Dynamic tensile strength of concrete $\mathrm{f}_{\mathrm{y}} \quad=$ Yield strength of steel

$\mathrm{h}=$ Height at which the explosive charge is located

$\mathrm{A}_{0} \quad=$ Area of the cross-section of the undamaged element

$\mathrm{A}_{\mathrm{ej}} \quad=$ Area of the finite element $\mathrm{i}$

$\mathrm{A}_{\mathrm{si}} \quad=$ Area of each reinforcement bar $\mathrm{i}$

$f_{s_{i}} \quad=$ Strength of the steel bar

$\mathrm{E}_{\mathrm{c}} \quad=$ Elastic modulus of concrete

$\mathrm{E}_{\mathrm{S}} \quad=$ Elastic modulus of steel

$\mathrm{G}_{\mathrm{Fd}} \quad=$ Dynamic fracture energy

$\mathrm{N}_{\mathrm{c}} \quad$ = Remaining capacity of the member

$\mathrm{N}_{\mathrm{d}} \quad=$ Demand load

$\mathrm{R} \quad=$ Distance from the blast source to the standoff point

$\mathrm{W} \quad=$ Explosive charge weight

$\mathrm{UCW}=$ Unit Charge Weight

$\varepsilon_{\mathrm{cd}} \quad=$ Dynamic strain at maximum stress of concrete

$v \quad=$ Poisson's ratio

$\eta \quad=$ Ratio of damage area to total area of the deck

\section{References}

1. Winget, D. G, Marchand, K. A., and Williamson, E. B., "Analysis and Design of Critical Bridges Subjected to Blast Loads," Journal of Structural Engineering, Aug. 2005, pp.1243 1255.

2. Nanni, A, Asprone, D., Ayoub, A., Baird, J., Filangieri, A., Galati, N., Kiger S., Marianos, N., Prota, A., Quintero, R., Wang, M., and Wei, J., Blast Testing and Research-Bridge at the Tenza Viaduct, Final Report Task 1 of TSWG Contract Number N4175-05-R-4828, University of Missouri-Rolla, Rolla, MO, USA, 2006.

3. ABAQUS, User's Manual, Version 6.5, Hibbitt, Karlsson and Sorensen, Inc. Pawtucket, RI, 2005.

4. ABAQUS, Theory Mamual, Hibbitt, Karlsson and Sorensen, Inc. Pawtucket, RI, 1997.

5. Comite Euro-International Du Beton, CEB-FIP Model Code 1990, Design Code, Thomas Telford, Trowbridge, Wiltshire, UK, 1993.

6. Malvar, L. J. and Ross, C. A., "Review of Strain Rate Effects for Concrete in Tension," ACI Materials Journal, Vol.95, No.6, 1998, pp.735 739.

7. Wei, J., Quintero, R., Galati N., and Nanni, A., "Failure Modeling of Bridge Components Subjected to Blast Loading. Part I: Strain Rate-Dependent Damage Model for Concrete," Submitted to International Journal of Concrete Structures and Materials (IJCSM), Oct. 2007.

8. Beshara, F. A., "Modeling of Blast Loading on Aboveground Structures? I. General Phenomenology and External Blast", Computers \& Structures, Vol.51, No.5, 1994, pp.585 596.

9. US Army Corps of Engineers, Suppressive Shields-Structural Design and Analysis Handbook, Report HNDM-1110-1-2, U.S. Army Corps of Engineers, Huntsville, AL, 1997.

10. Kinney, G. F. and Graham, K. J., Explosive Shocks in Air, New York, Springer-Verlag, Inc., 1985.

11. Luccioni, B. M., Ambrosini, R. D., and Danesi, R. F., “Analysis of Building Collapse under Blast Loads," Engineering Structures, Vol.26, 2004, pp.63 71. 